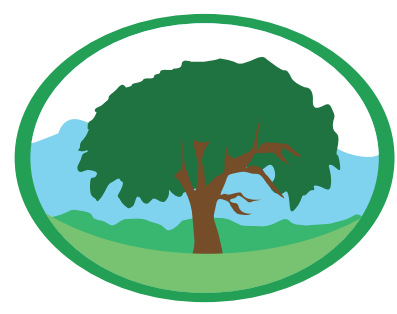

\title{
BIODEGRADABILIDADE DE COMPÓSITOS REFORC̣ADOS POR FIBRAS DE BANANA E DE BATATA-DOCE
}

TOMSEN, F.; DELUCIS, R. A.; VEIGA, F. C. T.; GATTO, D. A.; GONÇALVES, M. R. F.

Palavras-chave: fibras vegetais, compósitos, biodegradação.

\section{Resumo}

O desenvolvimento de novos materiais tem atraído atenção e dentro desse viés, o presente estudo analisou a durabilidade de compósitos reforçados com fibras de banana e de batata-doce, tendo o PVA como agente ligante, em formulações com híbridos e fibras únicas. No trabalho, foram conformadas três diferentes formulações, sendo as duas primeiras com fibras únicas de banana e de batatadoce e a última, hibridizando essas duas fibras. Nos ensaios de biodegradação em ambiente anaeróbio, o solo foi preparado segundo o procedimento G 160-03 da ASTM, com coletas periódicas de amostras ao longo de 12 semanas. As fibras foram caracterizadas quimicamente por via úmida (teores de lignina Klason e extrativos) e por microscopia ótica (presença de lignina residual). A biodegradabilidade dos compósitos foi avaliada por meio da perda de massa, colorimetria (método CIELAB), espectroscopia de infravermelho (FTIR), microscopia eletrônica de varredura (MEV) e espectroscopia de energia dispersiva (EDS). Nos resultados, os compósitos formulados com fibras de banana foram os que apresentaram maior resistência microbial e os compósitos híbridos apresentaram níveis intermediários de perda de massa e maior estabilidade colorimétrica.

\section{BIODEGRADABILITY OF BANANA AND SWEET POTATO FIBRES REINFORCED COMPOSITES}

Keywords: natural fibres, composites, biodegradation.

\section{Abstract}

Development of new materials has been attracted attention and in this sense, in the present study, the durability of banana and sweet potato reinforced composites was investigated, using the PVA as binder agent, in formulations with hybrids and single fibres. In the processing, three different formulations were conformed using the hot pressing process. For the biodegradation tests in anaerobic environment, the soil was prepared according to the procedure G 160-03 of ASTM, with periodic samplings over 12 weeks. The fibres were pre-characterized through the following assays: optical microscopy and characterization via wet (Klason lignin and extractives content). Biodegradability of composites was evaluated by weight loss, colourimetry (CIELAB method), infrared spectroscopy (FTIR), scanning electron microscopy (SEM) and energy dispersive spectroscopy (EDS). Based on the results, the composites made with banana presented higher microbial resistance than those from sweet potato. Compared to the single fibre composites, the hybrid composite presented intermediate weight loss and higher colour stability. 


\section{INTRODUÇÃO}

As políticas governamentais, tanto a nível nacional, quanto internacional, têm priorizado a utilização de matérias-primas de origem renovável para mitigar problemáticas como o impacto ambiental, por meio do desenvolvimento sustentável, vinculado a utilizaçáo de fontes vegetais. Nesse contexto, o uso de resíduos agrícolas e florestais destaca-se como uma alternativa viável devido às descobertas feitas nos últimos anos à respeito das tecnologias de reaproveitamento e às características técnicas desses materiais in natura (LE DIGABEL et al., 2004; TOMSIC et al., 2014) ou obtidas a partir de tratamentos (D'ALMEIDA et al., 2005; TOMSIC et al., 2014).

Um dos nichos para o emprego de resíduos de origem vegetal é a formação de materiais compósitos, onde tais recursos sustentáveis podem ser empregados em forma de fibras ou partículas, reforçando polímeros termoplásticos ou termorrígidos. Nesse contexto, quando utilizadas fibras de origem vegetal (natural fibers), a preferência ocorre pelas matrizes termoplásticas, como: o polipropileno (PP), o politereftalato de etileno (PET), o poli(álcool vinílico) (PVOH), o ácido poli (láctico) (PLA), o poli(óxido de etileno) (PEO), o policloreto de vinil (PVC), o poliestireno, o polietileno de baixa densidade (LDPE), o polietileno de baixa densidade linear (LLDPE), entre outros. Com relação às características dos materiais biológicos utilizados como reforço, a qualidade dos compósitos produzidos está vinculada às propriedades químicas (conteúdo de polissacarídeos amorfos e lignina) e morfológicas (comprimento e diâmetro) dessas fibras, as quais interferem em sua ligação com a matriz (GADIOLI et al., 2014).

$\mathrm{Na}$ área de polímeros, notadamente a inserção de materiais biodegradáveis como reforço para a produção biocompósitos poliméricos é uma das vias que mais apresenta crescimento, com base nas publicaçóes dos pesquisadores da área. Em consulta aos anais do principal congresso de materiais poliméricos do Brasil o Congresso Brasileiro de Polímeros (CBPol), ocorrido no ano de 2015, verifica-se que dos 1003 resumos expandidos submetidos ao evento, 195 foram enviados sob a área do conhecimento nomeada de "biopolímeros e polímeros biodegradáveis", o que corresponde a mais de $19 \%$ de todos trabalhos publicados. Essa área superou outros nichos tradicionais de desenvolvimento de pesquisas, tais como: blendas poliméricas, borrachas e elastômeros, reciclagem de polímeros, entre outros.

Por exemplo, o poliacetato de vinila (PVA) é um polímero sintético, termoplástico e amorfo. Possui boa adesão a muitas superfícies e, por isso, tem sido utilizado para diversas aplicaçôes, incluindo reparos gerais, como preenchimento de furos e imperfeições (JEBRANE et al., 2011). Também, sua utilização ocorre tipicamente na produçáo de tintas e outros materiais de construçáo (JEBRANE et al., 2011; ZIMMERMANN et al., 2014). Segundo Zimmermann et al. (2014), O PVA também é uma matriz promissora para compósitos poliméricos.

Dentre as alternativas de matérias-primas vegetais que podem ser utilizadas em biocompósitos, a batatadoce (Ipomoea batatas) pode ser destacada por ser uma das plantas alimentares introduzidas mais antigas do Brasil. Possui uma produção de 3 milhóes de toneladas anuais, cultivada do sul ao nordeste brasileiro (CAVALCANTE et al., 2009). Além da batata-doce, a banana (Musa sp.) também possui um grande potencial, pois é facilmente cultivada em países tropicais como o Brasil. Segundo Lichtemberg; Lichtemberg (2011), a área de cultivo da bananeira é de cerca 500.000 ha no Brasil, com uma produção de aproximadamente $7 \mathrm{mil}$ toneladas por ano, concentrada principalmente nos estados da Bahia, São Paulo, Santa Catarina, Minas Gerais e Pará.

Em âmbito mundial, a produção de banana ultrapassa 105 milhóes de toneladas, enquanto a de batata-doce está muito próxima a 100 milhóes de toneladas (FAO, 2020). A fim de estimar a quantidade de rejeitos produzida referente a essas culturas, Sagar et al. (2018) indicou que cerca de $35 \%$ da fruta de banana é rejeitada por se tratar da massa de casca, talos e ramas. Já quanto à batata-doce, esses autores reportaram $15 \%$ em massa em relação ao montante de rejeitos nesse vegetal.

Portanto, está claro que existe um custo significativo relacionado à necessidade de descarte de resíduos gerados pelo consumo dessas culturas, os quais poderiam ser reutilizados com vistas a novas finalidades. Desse modo, seu uso como reforço para a confecção 
de materiais compósitos (SAPUAN et al., 2006) e/ou compósitos híbridos (ARTHANARIESWARAN et al., 2014) deve ser encorajado. Tais materiais vegetais costumam ser empregados na produção de fios, cordas, capachos, estofados, vasos para plantas e etc. Conforme Horinouchi et al. (2008), a confecção de vasos biodegradáveis de compósitos híbridos, além de favorecer o crescimento das raízes das mudas plantadas nesses recipientes, facilita o descarte desses vasos após sua vida útil, pois estes se transformam em biomassa ou adubo. Também seria possível que esses vasos fossem plantados juntamente com a muda no plantio, sem necessidade de sua retirada.

O presente estudo objetivou produzir compósitos, utilizando o poliacetato de vinila (PVA) e fibras provenientes do talo da banana e rama da batata-doce e verificar sua biodegradabilidade.

\section{MATERIAL E MÉTODOS \\ Obtenção e preparação dos materiais de estudo}

Para o estudo, a matéria prima vegetal foi adquirida comercialmente em estabelecimentos do município de Pelotas, Rio Grande do Sul. O material consistiu em unidades de banana (Musa paradisiaca) e de batatadoce (Ipomoea batatas), das quais foram manualmente selecionados os talos e as ramas, respectivamente. Aproximadamente, a matéria-prima em estudo consistiu em $10 \mathrm{~kg}$ de cada cultura.

Para obtenção das fibras, as matérias primas vegetais foram seccionadas em $10 \mathrm{~mm}$ de comprimento. Em seguida, a fim de serem retirados excessos de biomassa e evitar a atividade microbiana, as matérias primas foram autoclavadas, em um equipamento da marca Phoenix, modelo AV18, sob as condiçôes de $127^{\circ} \mathrm{C}$ de temperatura e $1,5 \mathrm{kgf} . \mathrm{cm}^{-2}$ de pressão, durante 4 horas.

Após o alívio da pressão e o resfriamento, as fibras obtidas foram separadas em um liquidificador Industrial da marca Zottini, modelo industrial, funcionando com $30 \%$ de água, a uma velocidade de $500 \mathrm{~m} . \mathrm{s}^{-1}$, durante 5 minutos. Por fim, as fibras individualizas foram secas em estufa laboratorial com circulação natural de ar à temperatura de $30^{\circ} \mathrm{C}$, durante 24 horas. Após a secagem, as fibras foram moídas em um moinho da marca Marconi, modelo MA 340, e peneiradas em uma peneira \#35 sendo utilizado somente o material passante.

\section{Caracterização das fibras celulósicas}

Para a caracterização química das fibras, foram avaliados seus teores de extrativos solúveis em etanoltolueno pela norma T204 om-97 (TAPPI, 1997) e lignina Klason pela norma T222 om-98 (TAPPI, 1998). A presença de lignina residual foi confirmada por microscopia ótica, em um microscópio da marca Olptiun, modelo TNB-04T-PL. Para tanto, as fibras foram lavadas, fixadas em lâminas de vidro e coradas com azul de toluidina à $0,5 \%$.

\section{Fabricação dos compósitos}

Para a confecção dos compósitos, foram elaboradas três formulaçóes, com as quais foram confeccionados corpos de prova em uma prensa à frio, sob uma pressão de $20 \mathrm{kgf.} . \mathrm{cm}^{2}$, durante 3 minutos, nas dimensóes de $25 \mathrm{~mm} \times 25 \mathrm{~mm}$ × $3 \mathrm{~mm}$ (comprimento, largura e espessura, respectivamente). Na primeira formulação (T1), foi empregado um teor de fibras de banana e cola PVA de 92 e 8\%, respectivamente. Já na segunda (T2), foi utilizada a fibra de batata-doce na mesma proporção com a cola PVA (92 para 8\%). Enquanto na terceira formulação, foram formulados compósitos híbridos com teores de fibras de banana, batata-doce e cola PVA de 46, 46 e 8\%, respectivamente.

Com respeito as formulaçóes utilizadas, salienta-se que devido a inexistência de metodologia consolidada disponível na literatura, também foram testados compósitos com 1, 3 e 5\% em peso de ligante, os quais apresentaram-se desuniformes e sem a mínima rigidez para serem manuseados. Foram conformadas 21 amostras, conforme cada formulação, totalizando 63 amostras.

\section{Ensaio de biodegradabilidade dos compósitos}

Para a avaliação da biodegradabilidade das amostras, preparou-se uma formulação do solo simulado com 5 $\mathrm{kg}$ de solo com baixo teor de argila (solo proveniente de uma área de colheita de floresta de Pinus spp., em repouso por 60 dias), $5 \mathrm{~kg}$ de areia grossa e $5 \mathrm{~kg}$ de excremento de cavalo (esterco), totalizando $15 \mathrm{~kg}$ de substrato, conforme proposto na norma G 160-03 (ASTM, 2015). No procedimento, primeiramente, o 
solo e a areia grossa foram manualmente misturados durante $20 \mathrm{~min}$, recolhendo-se o material passante em uma peneira de 45 mesh. Posteriormente, o material passante foi manualmente misturado ao esterco, até visualmente ser verificada a homogeneidade da mistura.

O solo obtido foi armazenado em um recipiente coberto por uma tela de algodáo, sob condiçóes climatológicas ambientais, durante três meses. Para garantir sua maturação homogênea, o solo simulado foi misturado a cada três dias. Para verificar a maturação do solo, foram preparados em triplicata corpos de prova de tecido de algodáo no formato de tiras, nas dimensóes de $50 \times 500 \mathrm{~mm}$ (largura e comprimento, respectivamente) e gramatura de $400 \mathrm{~g} \cdot \mathrm{m}^{-2}$, os quais foram enterrados no solo simulado, durante cinco dias. Transcorrido o tempo de envelhecimento, foi comprovado visualmente que as tiras se degradaram, indicando a condiçáo adequada do solo para os testes de biodegradabilidade.

O ensaio de biodegradabilidade foi realizado em condição anaeróbia. Para tanto, foram preparados fracos de vidro preenchidos em 2/3 de solo simulado. As amostras das três formulaçóes foram enterradas nos fracos, que foram tampados e armazenados em uma estufa de cultura bacteriológica com circulação de ar e refrigeração, da marca Nova Ética, modelo 410 DR. Além disso, a atmosfera das amostras em estudo foi preparada mediante aplicaçáo de vácuo para retirada do oxigênio, o que ocorreu com auxílio de uma bomba de vácuo e um dessecador. Para monitorar o processo de biodegradação, foram coletadas amostras na $1^{\mathrm{a}}, 4^{\mathrm{a}} \mathrm{e}$ $12^{\text {a }}$ semanas, totalizando 3 amostragens.

\section{Caracterização dos compósitos}

A caracterização das amostras biodegradadas e do grupo de amostras controle (amostras que não foram biologicamente ensaiadas) foi através de técnicas de macroscopia, espectroscopia e microscopia. Macroscopicamente, as amostras foram caracterizadas fotograficamente utilizando-se uma câmera fotográfica de 5MP. Adicionalmente, foi calculada a perda de massa porcentual das amostras (Equação 1), por meio de pesagens realizadas anterior e posteriormente ao ensaio biológico, nas quais utilizou-se uma balança analítica com resolução de $0,001 \mathrm{~g}$.

$$
\operatorname{Pm}(\%)=\frac{(m i-m f)}{m i} \cdot 100
$$

Em que: $\operatorname{Pm}(\%)=$ perda de massa porcentual; $\mathrm{mi}=$ massa inicial $(\mathrm{g}) ; \mathrm{mf}=$ massa final $(\mathrm{g})$.

$\mathrm{O}$ aspecto físico dos compósitos foi caracterizado com a análise da cor, por meio de um colorímetro portátil, da marca Konica Minolta, modelo CR-400 com abertura de sensor de $8 \mathrm{~mm}$. O equipamento foi adaptado para utilização de fonte de luz (iluminante) D65 e ângulo de observaçáo de $10^{\circ}$, de acordo com padróes estabelecidos pela CIEL*a*b* (DELUCIS et al., 2014). Nessa avaliaçáo foram obtidos como parâmetros colorimétricos: a luminosidade $\left(\mathrm{L}^{*}\right)$ e as coordenadas cromáticas verde-vermelho $\left(\mathrm{a}^{*}\right)$ e azulamarelo $\left(b^{*}\right)$. Para dessas propriedades colorimétricas, a estabilidade colorimétrica dos compósitos foi avaliada pelo $\Delta \mathrm{E}$ (Equação 2), comparando-se o grupo de compósitos controle com os compósitos retirados após 12 semanas de teste biológico.

$$
\Delta \mathrm{E}=\sqrt{\Delta \mathrm{L}^{* 2}+\Delta \mathrm{a}^{* 2}+\Delta \mathrm{b}^{* 2}}
$$

Em que: $\Delta \mathrm{E}$ - variação de cor; $\mathrm{L}^{*}$ - luminosidade; $a^{*}$ - coordenada cromática verde-vermelho; $b^{*}$ coordenada cromática azul-amarelo.

As modificaçóes ocorridas na estrutura química dos compósitos em razão do processo de biodegradação foram avaliadas com a técnica de espectroscopia de infravermelho (ATR-IR), consultando-se o banco de dados de picos. As análises foram conduzidas em equipamento da marca Cromate, modelo Jasco FT/IR - 4100. Para cada amostra, foram acumulados cerca de 40 scans automáticos, em uma resolução $4 \mathrm{~cm}^{-1}$, obtendo-se espectros em transmitância, num rango de números de onda entre 4000 e $500 \mathrm{~cm}^{-1}$.

Em adição, a interface reforço-matriz dos compósitos e suas modificaçóes atribuídas ao processo de biodegradação foram observadas por microscopia eletrônica de varredura (MEV), em um equipamento da marca JEOL, modelo JMS T-5800, configurado para uma tensão de aceleração do feixe de elétrons de $20 \mathrm{kV}$. Para tanto, os compósitos foram metalizados com ouro pela técnica de sputtering. Por fim, analisouse a composição química pelo método quantitativo de 
espectroscopia de energia dispersiva (EDS), por meio de uma sonda acoplada ao MEV supramencionado.

\section{RESULTADOS E DISCUSSÃO}

Os níveis médios para os teores de extrativos para as fibras de banana e batata-doce foram de 1,204 e $1,389 \%$, respectivamente. Já para os níveis de lignina Klason, foram obtidos os valores médios de 17,58 e $20,77 \%$ para as fibras de banana e batata-doce, respectivamente. Tais teores de extrativos e lignina Klason apresentaram-se semelhantes entre si, com sensível superioridade para a fibra de batata-doce. Em comparação com a literatura, verifica-se que os níveis de extrativos e lignina Klason estão dentro da faixa reportada em estudos anteriormente publicados para fibras de origem vegetal, extraídas com a finalidade de preparar compósitos poliméricos, a qual é de 2 a $16 \%$ (LE DIGABEL et al., 2004; TELMO; LOUSADA, 2011) e 22,2 a 41,4\% (TELMO; LOUSADA, 2011), respectivamente.

Com relação aos compósitos obtidos a partir dessas fibras, verifica-se que a perda de massa ao longo do ensaio biológico foi predita de modo eficaz pelos modelos matemáticos (Figura 1). Nesse sentido, verifica-se que em todas as formulaçóes de compósitos, 95\% ou mais dos dados foram preditos corretamente pelos modelos polinomiais ajustados.

\begin{tabular}{|c|c|c|c|c|}
\hline & \multicolumn{2}{|l|}{ Equação } & $\mathrm{R}^{2}$ & Razão-F \\
\hline $\mathrm{T} 1$ & \multicolumn{2}{|c|}{$y=10,5861+3,44398 \cdot x+0,142184 \cdot x^{2}$} & 0,98 & $149,88^{*}$ \\
\hline T2 & \multicolumn{2}{|c|}{$y=11,9029-0,278013 \cdot x+0,397206 \cdot x^{2}$} & 0,98 & $213,53 * *$ \\
\hline T3 & \multicolumn{2}{|c|}{$y=16,0002-0,508941 \cdot x+0,415863 \cdot x^{2}$} & 0,95 & $55,68 * *$ \\
\hline \multicolumn{5}{|c|}{80} \\
\hline \multicolumn{5}{|c|}{70} \\
\hline \multicolumn{5}{|c|}{60} \\
\hline \multicolumn{5}{|c|}{50} \\
\hline \multicolumn{5}{|c|}{$\Xi_{30}$} \\
\hline \multicolumn{5}{|c|}{20} \\
\hline \multicolumn{5}{|c|}{10} \\
\hline \multicolumn{5}{|c|}{12} \\
\hline & \multicolumn{4}{|c|}{ Tempo em teste biológico } \\
\hline
\end{tabular}

Figura 1. Níveis de perda de massa (Pm\%) ao longo do ensaio biológico e suas linhas tendências. Em que: y - perda de massa porcentual (\%); $x$ - tempo em teste biológico (semanas); T1- compósito de banana; T2- compósito de batatadoce; T3- compósito híbrido banana/batata-doce.

O compósito híbrido (T3) apresentou níveis de perda de massa aproximadamente intermediários aos formulados com fibras de banana (T1) e de batatadoce (T2). Outra característica observada trata da inexistência de influência dos teores de lignina Klason e extrativos (Figura 3) na biodegradabilidade dos compósitos, pois esperava-se que devido a presença de compostos fenólicos, que lhes conferem um caráter recalcitrante (GADIOLI et al., 2014; SANTOS et al., 2014), o maior conteúdo de lignina e extrativos fosse proporcionar uma maior resistência microbial ao compósito de batata-doce, o que não ocorreu.

Ainda com relação aos compósitos híbridos (T3), pode-se verificar que não houve adição sinérgica de fibras em sua formulação, pois os níveis de perda de massa observados não são maiores do que os esperados com base na lei das misturas. Conforme José; Prado (2005), o sinergismo dos constituintes da mistura em um compósito híbrido depende principalmente da natureza química dos segmentos orgânicos e inorgânicos e do tamanho e morfologia dos seus correspondentes domínios. Desse modo, as propriedades finais de um 
compósito hibrido não será apenas condicionada a contribuiçôes individuais de seus componentes.

Após 12 semanas de ensaio biológico, em média, todos os compósitos obtiveram perda de massa superior à $60 \%$, o que indica a eficácia da metodologia empregada, no tocante ao tempo proposto. Embora tenham sido verificados níveis semelhantes de perda de massa, na aplicação da análise estatística houve diferenciação significativa tanto na comparação entre os compósitos $(\mathrm{F}=3,51 ; \mathrm{p}<0,05)$, quanto entre as coletas realizadas ao longo do ensaio $(\mathrm{F}=334,62$; $\mathrm{p}<0,01)$.

Em relação ao aspecto físico dos compósitos ao longo do ensaio biológico, numa vista a olho nu (Figura 2), verifica-se que a coloração original dos compósitos (Figura 2), verifica-se que o compósito constituído de fibras da rama da batata-doce apresenta uma coloração mais clara, seguida do compósito híbrido (T3).

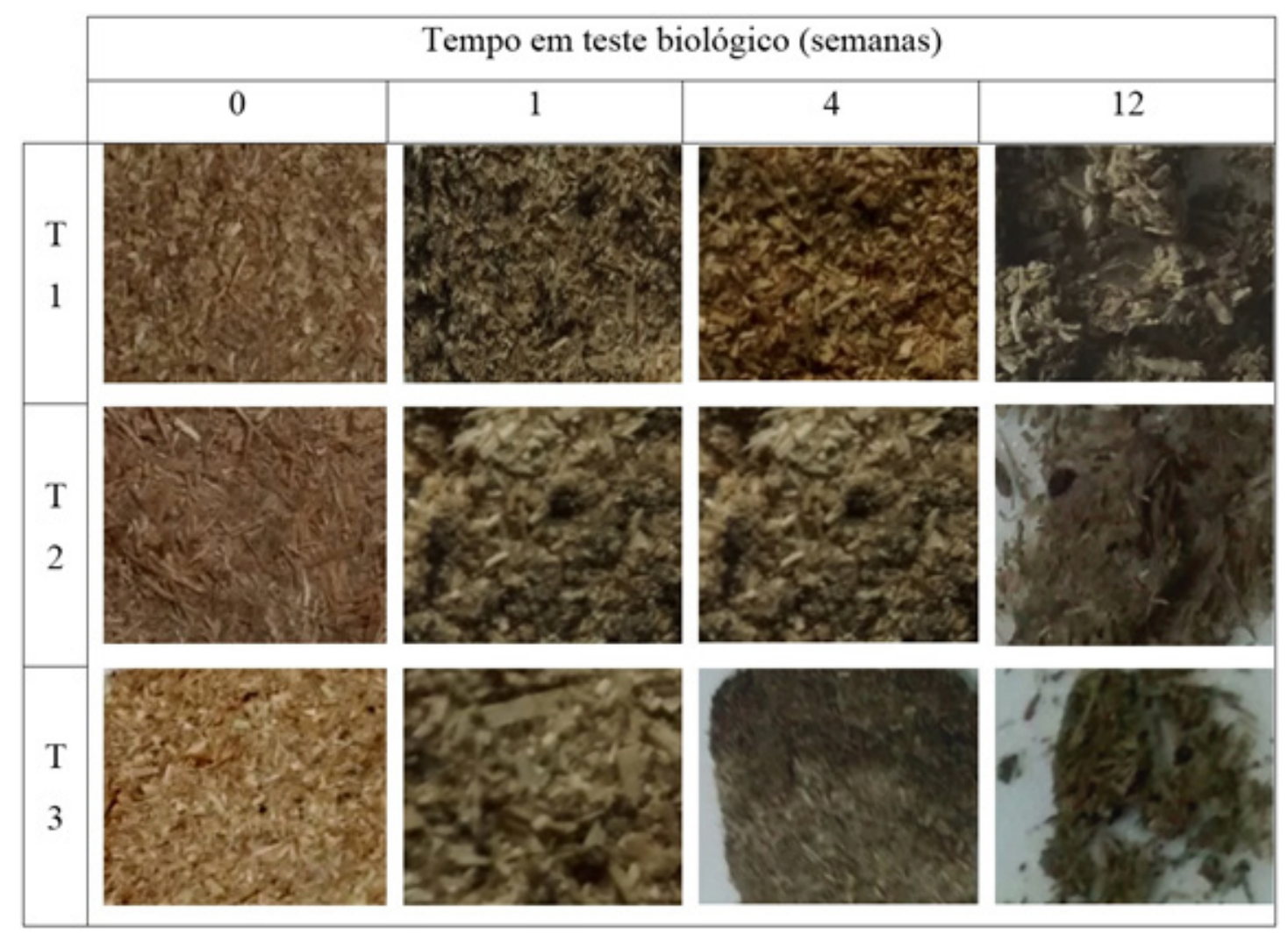

Figura 2. Fotografias dos compósitos ao longo do ensaio biológico. Em que: T1- compósito de banana; T2- compósito de batata-doce; T3- compósito híbrido banana/batata-doce.

A perda de boa parte da massa original dos compósitos ao final das 12 semanas de teste biológico foi visualizada nas fotos exibidas na Figura 2, o que se torna a comprovaçáo dos níveis de perda de massa exibidos na Figura 1. Outro quesito notável, se trata da perda da coloração original das amostras, as quais adquiriram coloração acinzentada. $\mathrm{Na}$ comparação entre as formulaçóes, analogamente à perda de massa, verifica-se que o compósito híbrido apresenta propriedades intermediárias às outras duas formulações.

Com relação à alteração da coloração dos compósitos atribuída ao processo de biodegradação durante o ensaio biológico (Figura 3), foi possível notar que em todos os compósitos houve uma tendência ao aumento dos níveis de $L^{*}$, bem como tendência à diminuição dos níveis de $\mathrm{a}^{*}$ e $\mathrm{b}^{*}$.

O declínio nos níveis de L*, a* e b* (Figura 3) representa o escurecimento das amostras, juntamente com a perda de seus pigmentos avermelhados e amarelados, respectivamente. Tal comportamento se mostra condizente na comparação com o envelhecimento natural reportado em estudos anteriormente publicados para diversos materiais biológicos, como fibras vegetais (TOMSIC et al., 2014), madeira (DELUCIS et al., 2016), compósitos (MATTOS et al., 2015) e biocompósitos (ARANGUREN et al., 2012; MASEK et al., 2014). 


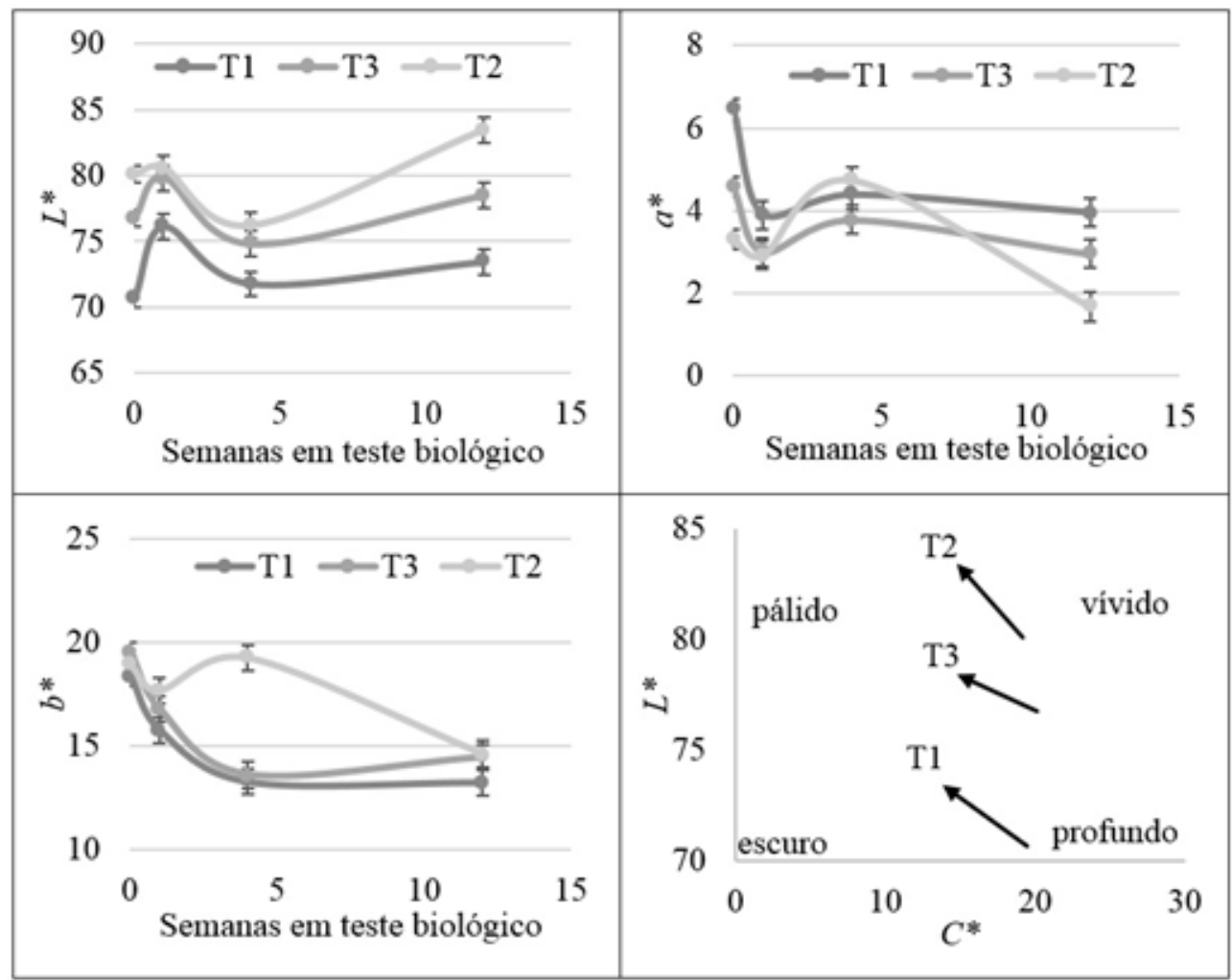

Figura 3. Níveis de $L^{*}, a^{*}$ e b* ao longo do ensaio biológico e gráfico de cromaticidade. Em que: T1- compósito de banana; T2- compósito de batata-doce; T3- compósito híbrido banana/batata-doce.

Peculiarmente, de modo diferente dos níveis de perda de massa, a depreciação da cor dos compósitos se mostrou mais intensa na primeira semana de degradação. Após, até a quarta semana houve uma descoloração em menor intensidade e por fim, até a décima segunda de testebiológico, houve uma tendência a estabilização dos níveis de cor dos compósitos. Portanto, é possível dividir em duas etapas as causas da descoloração dos compósitos: a primeira etapa, até a $4^{\mathrm{a}}$ semana, que é atribuída a absorção de luz da parte dos grupos cromóforos da lignina (GEORGE et al., 2005; PANDEY, 2005), e a segunda etapa, até a $12^{\mathrm{a}}$ semana, que ocorreu devido à infestação dos agentes biológicos de degradação (fungos e bactérias) (DELUCIS et al., 2016).

Colorimetricamente, a biodegradação foi caracterizada pelo acinzentamento e o empalidecimento dos compósitos, que estiveram associados ao acréscimo dos níveis de luminosidade e a diminuição dos pigmentos avermelhados e amarelados. Com relação à estabilidade colorimétrica, verificou-se que os componentes da mistura dos compósitos híbridos comportaram-se sinergicamente ao longo do processo de biodegradação.

Quanto aos gráficos de cromaticidades, o aumento dos níveis de $\mathrm{L}^{*}$, concomitante ao crescimo dos níveis de $C^{*}$, segundo o manual de colorimetria da Konica Minolta (2007), vetorialmente aponta para uma coloração mais pálida. Portanto, o acinzentamento verificado nas fotografias dos compósitos está associado ao acréscimo dos níveis de $\mathrm{L}^{*}$, concomitante ao decréscimo dos níveis de $\mathrm{C}^{*}$.

Com relação à estabilidade colorimétrica, os compósitos T1, T2 e T3 apresentaram valores médios de $\Delta \mathrm{E}$ iguais a $19,93,20,00$ e 11,92 , respectivamente. Em consideração ao gráfico de cromaticidade (Figura 3), verifica-se que independentemente do tipo de compósito, os níveis de $\mathrm{L}^{*}$ aumentaram, enquanto os de $C^{*}$ decresceram.

Os níveis de $\Delta \mathrm{E}$ obtidos indicaram que os componentes da formulação dos compósitos T3 agiram sinergicamente, pois seus níveis de $\Delta \mathrm{E}$ não seriam previsíveis pela lei das misturas, de modo que com relação à estabilidade colorimétrica, estes foram superiores aos outros dois compósitos (T1 e T2).

Quanto à constituição química dos compósitos analisada pela espectroscopia de infravermelho (Figura 4), em comparação com o banco de dados de picos obtidos nos trabalhos de Le Troëdec et al. (2009) e Dai; Fan (2001), na formulação T1 verifica-se um pico em 
$1035 \mathrm{~cm}^{-1}$ que é atribuído à vibraçóes de anel e grupos laterais $\mathrm{C}-\mathrm{C}, \mathrm{C}-\mathrm{OH}, \mathrm{C}-\mathrm{H}$ dos polissacarídeos. Já para a formulaçáo T2, verificam-se picos em 1730, 1370,1240 e $1035 \mathrm{~cm}^{-1}$, que representam vibração de estiramento $\mathrm{C}=\mathrm{O}$ na celulose, deformação no plano $\mathrm{CH}$ nos polissacarídeos, grupo arilo $\mathrm{C}-\mathrm{O}$ na lignina e vibraçôes de anel e grupos laterais $\mathrm{C}-\mathrm{C}, \mathrm{C}-\mathrm{OH}, \mathrm{C}-\mathrm{H}$ dos polissacarídeos, respectivamente.

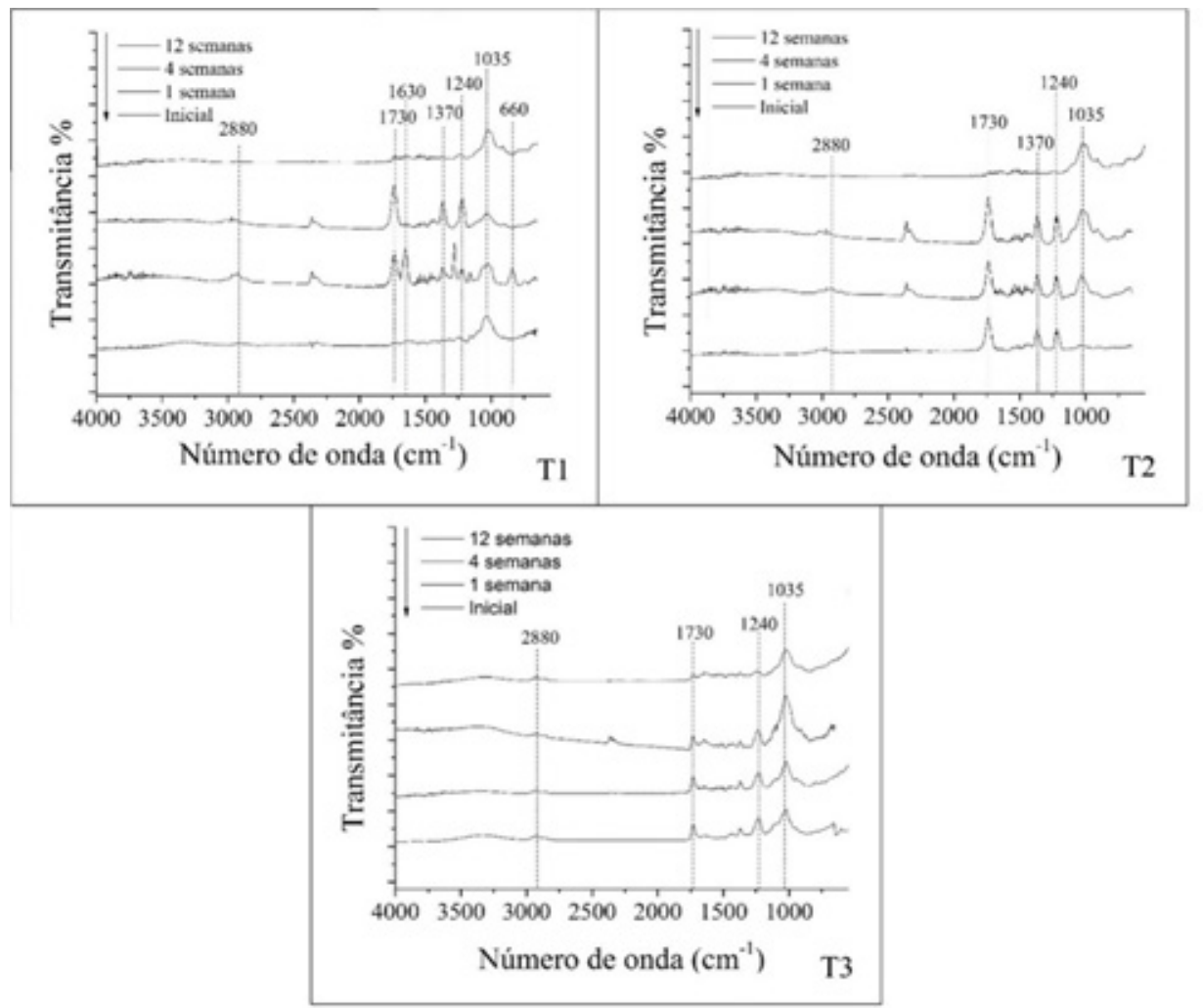

Figura 4. Espectros infravermelho dos compósitos em razão do tempo em teste biológico. Em que: T1- compósito de banana; T2- compósito de batata-doce; T3- compósito híbrido banana/batata-doce.

Nos espectrogramas de infravermelho, o maior número de picos verificados nas amostras biodegradadas atribuídos aos polissacarídeos comprova que a maior presença de lignina residual nas fibras de batata-doce foram identificadas nos compósitos T2, diferentemente dos formulados com banana (T1), lembrando que esse conteúdo de lignina não influenciou na resistência microbial dos compósitos, com base nos níveis de perda de massa e parâmetros colorimétricos.

Nos compósitos formulados com fibra de banana (T1) ainda foi verificado um pico em $1630 \mathrm{~cm}^{-1}$ atribuído a deformação em razão da absorção de água. Esse fenômeno pode explicar a menor resistência à biodegradação dos compósitos $\mathrm{T} 1$, pois a entrada de água na fibra promove uma maior rugosidade da mesma, que por sua vez, dá suporte ao crescimento microbiano.

Conforme Aranguren et al. (2012), as ligaçóes fortes entre as fibras naturais e a matriz biodegradável formam uma barreira contra a degradação hidrolítica.
No entanto, na medida em que a água penetra nos compósitos, essas ligações são hidrolisadas, criando meio favorável à proliferação de fungos. Esse efeito prejudicial proveniente da ação da água poderia ser reduzido mediante um tratamento físico ou químico na fibra vegetal, ou mesmo a utilização de um agente de acoplamento (e.g. anidrido maleico), capaz de aumentar a afinidade química entre a matriz e o reforço. Dentre os tratamentos mais comumente utilizados, é possível citar a silanização, tratamentos térmicos e hidrotérmicos, entre muitos outros (MOURA et al. 2018; SILVA et al., 2019).

Ainda com base nos espectros de infravermelho, para todos os compósitos, verifica-se que o pico em $1240 \mathrm{~cm}^{-1}$ correspondente ao grupo arilo da lignina vai gradativamente aparecendo com menor intensidade, chegando a desparecer nas amostras retiradas após 12 semanas de ensaio. Esse comportamento pode ser um indício do fenômeno descrito por George et al. (2005), Pandey (2005) e Delucis et al. (2016), e reportado no 
presente trabalho quando na discussão dos resultados de colorimetria. Tais autores reportaram que a lignina é degradada a partir de seus grupos cromóforos, de modo que posteriormente permanece suscetível à ser lixiviada da superfície das fibras naturais. Portanto, levando em conta que os compósitos foram levemente limpos por imersão ligeira em água, é pertinente asseverar que a lignina residual foi progressivamente degradada e lixiviada durante o processo de biodegradaçáo descrito no presente estudo.

Os picos em 1370 e $2880 \mathrm{~cm}^{-1}$ evidenciados em todos os compósitos nas primeiras coletas de amostras, que não aparecerem nos coletados após as 12 semanas de testes biológico, estão associados à parte amorfa dos polissacarídeos (D'ALMEIDA et al., 2005; ALBINANTE et al., 2013). Portanto, sua desaparição nos compósitos mais decompostos pode ser explicada pela degradaçáo da parte amorfa dos polissacarídeos, a qual ocorre primeiro do que a parte cristalina durante o processo de biodegradaçáo (KUMAR; KHANNA, 2014).

Por fim, a partir da análise micrográfica das amostras degradadas retiradas após 12 semanas de teste biológico (Figura 5) contata-se a biodegradação ocorrida nos compósitos com fibras únicas de banana (T1) e batata-doce (T2), bem como no compósito formulado pela hibridização dessas fibras (T3). Nas micrografias eletrônicas verifica-se um maior número de fibras intactas no compósito T1, na comparação com os demais compósitos (T2 e T3). Além disso, nessa comparaçáo, o compósito T3 aparece como intermediário aos outros dois compósitos. O que confirma os resultados obtidos com as análises de perda de massa e colorimetria.

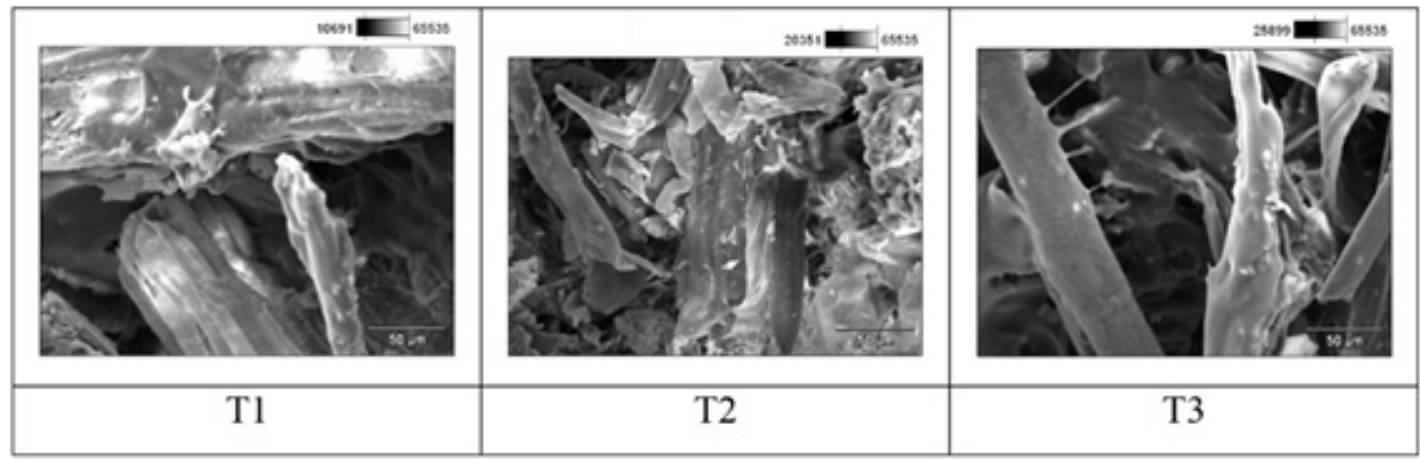

Figura 5. Micrografias dos compósitos ao longo do ensaio biológico. Em que: T1- compósito de banana; T2- compósito de batata-doce; T3- compósito híbrido banana/batata-doce.

Ainda a partir das micrografias exibidas na Figura 5, definiu-se a composição elementar dos compósitos por meio da técnica de espectroscopia de energia dispersiva (EDS), a qual pode ser parcialmente atribuída ao compósito in natura (C em teores entre 21 e 31\%; ), ao processo de biodegradação ( $\mathrm{Si}$ em teores entre 11 e $25 \%$ ), ao solo argiloso ( $\mathrm{Al}$ em teores entre 5 e $12 \%$; $\%$; Fe em teores entre 3 e 9\%; $\mathrm{K}$ em teores entre 1 e $2 \%$; Ca em teores entre 0,5 e 2) e à preparação dos compósitos para a análise (Au em teores entre 22 e $51 \%)$.

\section{CONCLUSÕES}

Todos os compósitos em estudo (seja o híbrido ou aqueles obtidos com fibras únicas) foram tecnicamente viáveis do ponto de vista de sua confecção. O compósito de batata-doce apresentou maior biodegradabilidade que o compósito de banana, enquanto o compósito híbrido apresentou um nível intermediário. Contudo, todos compósitos apresentaram uma alta taxa de biodegradação, especialmente após 12 semanas de contato com o solo.

Os teores de lignina e extrativos não tiveram qualquer influência nos níveis de resistência à biodegradação dos compósitos. Os compósitos em estudo parecem ter potencial para serem aplicados enquanto peças decorativas, capachos, vasos, entre outros usos. Entretanto, definir essa aplicabilidade demanda que resultados mais assertivos sejam publicados em estudos posteriores.

\section{LITERATURA CITADA}

ALBINANTE, S.R.; PACHECO, E.B.A.V.; VISCONTE, L.L.Y. Revisão dos tratamentos químicos da fibra natural para mistura com poliolefinas. Química Nova, v. 36, n. 1, p. 114-122, 2013. 
AMERICAN SOCIETY OFTESTING MATERIALS ASTM. Standard practice for evaluating microbial susceptibility on nonmetallic materials by Laboratory soil burial. Philadelphia: ASTM. G 160 - 03, 2015.

ARANGUREN, M.I.; GONZÁLEZ, J.F; MOSIEWICKI, M.A. Biodegradation of a vegetable oil based polyurethane and wood flour composites. Polymer Testing, v. 31, n. 1, p. 7-15, 2012.

ARTHANARIESWARAN, V.P.; KUMARAVEL, A.; KATHIRSELVAM, M. Evaluation of mechanical properties of banana and sisal fiber reinforced epoxy composites: Influence of glass fiber hybridization. Materials \& Design, v. 64, n. 12, p. 194-202, 2014.

CAVALCANTE, M.; FERREIRA, P.V.; PAIXÃO, S.L.; COSTA, J.G.; PEREIRA, R.G.; MADALENA, J.A.S. Potenciais produtivo e genético de clones de batata-doce. Acta Scientiarum Agronomy, v. 31, n. 3, p. 421-426, 2009.

D'ALMEIDA, A.L.F.S.; CALADO, V.; BARRETO, D.W. Acetilação da Fibra de Bucha (Luffa cylindrica). Polímeros: Ciência e Tecnologia, v. 15, n. 1, p. 5962, 2005.

DAI, D.; FAN, M. Investigation of the dislocation of natural fibres by Fourier-transform infrared spectroscopy. Vibrational Spectroscopy, v. 55, n. 2, p. 300-306, 2011.

DELUCIS, R.A.; CADEMARTORI, P.H.G.; MISSIO, A.L.; GATTO, D.A. Decay resistance of four fast-growing eucalypts wood exposed to three types of fields. Maderas Ciencia y Tecnologia, v. 18, n. 1, p. 33-42, 2016.

DELUCIS, R.A.; TABORDA, V.C.; CORREA, L.W.; VEGA, R.A.; GATTO, D.A. Avaliação da cor dos lenhos juvenil e adulto de cedro por meio do método CIEL*a*b*. Tecnologia em Metalúrgica, Materiais e Mineraçáo, v. 11, n. 3, p. 251-259, 2014.
Food and Agriculture Organization of the United States - FAOSTAT. 2020. Disponível em: http://www. fao.org/faostat/en/\#home

GADIOLI, R.; MORAIS, J.A.; WALDMAN W.R.; DE PAOLI, M.A. The role of lignin in polypropylene composites with semi-bleached cellulose fibers: Mechanical properties and its activity as antioxidant. Polymer Degradation and Stability, v. 108, n. 10, p. 23-34, 2014.

GEORGE,B.;SUTTIEB,E.;MERLIN,A.;DEGLISE, $X$. Photodegradation and photostabilisation of wood - the state of the art. Polymer Degradation and Stability, v. 8, n. 2, p. 268-274, 2005.

HORINOUCHI, H.; KATSUYAMA, N.; TAGUCHI, Y.; HYAKUMACHI, M. Control of Fusarium crown and root rot of tomato in a soil system by combination of a plant growth-promoting fungus, Fusarium equiseti, and biodegradable pots. Crop Protection, v. 27, n. 3-5, p. 859-864, 2008.

JEBRANE, M.; PICHAVANT, F.; SÈBE, G. A comparative study on the acetylation of wood by reaction with vinyl acetate and acetic anhydride. Carbohydrate Polymers, v. 83, n. 2, p. 339-345, 2011.

JOSÉ, N.M.; PRADO, L.A.S.A. Materiais híbridos orgânico-inorgânicos: preparação e algumas aplicaçôes. Química Nova, v. 28, n. 2, p. 281-288 2005.

KONICA MINOLTA. Precise color communication: color control from perception to instrumentation. Japan: Konica Minolta Sensing Inc. 2007.

KUMAR, M.; KHANNA, S. Shift in microbial population in response to crystalline cellulose degradation during enrichment with a semi-desert soil. International Biodeterioration \& Biodegradation, v. 88, n. 3, p. 134-141, 2014.

LE DIGABEL, F.; BOQUILlON, F.; DOLE, 
P.; MONTIES, B.; AVEROUS, L. Properties of Thermoplastic Composites Based on Wheat-Straw Lignocellulosic Fillers. Journal of Applied Polymer Science, v. 93, n. 1, p. 428-436, 2004.

LE TROËDEC, M.; PEYRATOUT, C.S.; SMITH, A.; CHOTARD, T. Influence of various chemical treatments on the interactions between hemp fibres and a lime matrix. Journal of the European Ceramic Society, v. 29, n. 10, p. 1861-1868, 2009.

LICHTEMBERG, L.A.; LICHTEMBERG, P.S.F. Avanços na bananicultura brasileira. Revista Brasileira de Fruticultura, v. 33, n. especial, p. 29-36, 2011.

MASEK, A.; ZABORSKI, M.; PIOTROWASKA, M. Controlled degradation of biocomposites ENR/PCL containing natural antioxidants. Comptes Rendus Chimie, v. 17, n. 11, p. 1128-1135, 2014.

MATTOS, B.D.; CADEMARTORI, P.H.G.; MAGALHÃES, W.E.; LAZAROTTO, M.; GATTO, D.A. Thermal tools in the evaluation of decayed and weathered wood polymer composites prepared by in situ polymerization. Journal of Thermal Analysis and Calorimetry, v. 121, n. 3, p. 1263-1271, 2015.

MOURA, A.; BOLBA, C.; DEMORI, R.; LIMA, L.P.F.C.; SANATANA, R.M.C. Effect of rice husk treatment with hot water on mechanical performance in poly(hydroxybutyrate)/rice husk biocomposite. Journal of Polymers and the Environment, v. 26, p. 2632-2639, 2018.

PANDEY, K.K. A note on the influence of extractives on the photo-discoloration and photo-degradation of wood. Polymer Degradation and Stability, v. 87, n. 2, p. 375-379, 2005.

SAGAR, N.A.; PAREEK, S.; SHARMA, S.; YAHIA, E.M.; LOBO, M.G. Fruit and Vegetable Waste: Bioactive Compounds, Their Extraction, and Possible Utilization. Comprehensive Reviews in Food Science and Food Safety, v. 17, n. 3, 512-531, 2018.
SAPUAN, S.M.; LEENIE, A.; HARIMI, M.; BENG, Y.K. Mechanical properties of woven banana fibre reinforced epoxy composites. Materials and Design, v. 27, n. 8, p. 689-693, 2006.

SANTOS P.S.B.; CADEMARTORI, P.H.G.; PRADO, R.; GATTO, D.A.; LABIDI, J. Composition and structure of organosolv lignins from four eucalypt species. Wood Science and Technology, v, 48, n. 4, p. 873-885, 2014.

SILVA, A.M.B.; LUZ, S.M.; SIVA, I.; JAPPES, J.T.W.; AMICO, S.C. Effect of silane treatment on the curaua fibre/polyester interface. Plastics, Rubber and Composites, v. 48, n. 4, p. 160-167, 2019.

TAPPI - T204, 1997. Solvent Extractives of Wood and Pulp 2000-2001 TAPPI Test Methods.

TAPPI - T222, 1998. Acid-insoluble Lignin in Wood and Pulp 2000-2001 TAPPI Test Methods.

TELMO, C.; LOUSADA, J. The explained variation by lignin and extractive contents on higher heating value of wood. Biomass and Bioenergy, v. 35, n. 5, p. 1663-1667, 2011.

TOMSIC, B.; ILEC, E.; ZERJAV, M.; HLADNIK, A. SIMONCIC, A.; SIMONCIC, B. Characterisation and functional properties of antimicrobialbio-barriers formed by natural fibres. Colloids and Surfaces B: Biointerfaces, v. 122, n. 10, p. 72-78, 2014.

ZIMMERMANN, M.V.; TURELLA, T.C.; ZATTERA, A.J.; SANTANA, R.M. Influência do tratamento químico da fibra de bananeira em compósitos de poli (etileno-co-acetato de vinila) com e sem agente de expansão. Polímeros, v. 24, n. 1, p. 58-64, 2014. 